\title{
DO TRADICIONAL AO INOVADOR: A HISTÓRIA DA FISIOTERAPIA, DE DISCIPLINA A PROGRAMA DE APRENDIZAGEM
}

\author{
Marciane Maria Kulczyck* \\ Jayme Ferreira Bueno*
}

\section{Resumo}

Este artigo enfoca a mudança da disciplina História da Fisioterapia, que se transformou no Programa de Aprendizagem Determinantes Históricos, Sociais e Culturais da Fisioterapia. Tal mudança ocorreu com a implantação do Projeto Pedagógico da PUCPR. Primeiramente, aborda o ensino tradicional, caracterizado pela relação vertical professor-aluno, e o ensino inovador, no qual essa relação se configura como uma relação horizontal, mais adequada à busca do conhecimento. Relata as mudanças metodológicas ocorridas e como elas influenciaram positivamente ao dinamizar o aprendizado dos discentes no referido Programa de Aprendizagem.

Palavras-chave: Educação, Ensino tradicional, Ensino inovador, Disciplina, Programa de aprendizagem, História da fisioterapia.

\section{Abstract}

This article presents the changes occurred in the subject of Physiotherapy History. First of all, the name of this subject changed to Learning Program of Historical, Social and Cultural Determiners of Physiotherapy. The modification happened because of the introduction of the Pedagogical Project in PUCPR. This article also focus the traditional teaching with the vertical relationship between professor and student and the new way of teaching. From now on this relation turns to horizontal and increases the search of knowledge. Finally, the article relates the methodological alterations occurred and how these changes influenced and gave dynamism to the student's learning in the mentioned program.

Keywords: Education, Traditional teaching, Innovator teaching, Discipline, Learning program, History of phiotherapy.

\footnotetext{
Mestre em Educação pela PUCPR. Professora do Curso de Fisioterapia - PUCPR.

Rua: João Kaviski, n. ${ }^{\circ}$ 72, Campina do Siqueira, Curitiba - PR, CEP 80730-260.

E-mail: mmk@rla01.pucpr.br

* Doutor em Letras pela USP. Professor do Mestrado em Educação - PUCPR.

Rua: Claudio Chatagnier, n. ${ }^{0}$ 267, Jardim Social, Curitiba - PR, CEP 82520-590.

E-mail: rjbueno@qwnet.com.br
} 


\section{Introdução}

Muitos autores vêm escrevendo sobre a mudança dos paradigmas da ciência que influenciam a educação, principalmente sobre a passagem do paradigma tradicional para o paradigma inovador. É importante que se entenda o que é um paradigma e quais as transformações ocorridas, para que se esclareça a influência dessas mudanças no aprendizado.

O conceito de paradigma se torna claro no texto de Aranha (1996, p.235): "um paradigma é um modelo, um conjunto de idéias e valores capaz de situar os membros de uma comunidade em determinado contexto, de maneira a possibilitar a compreensão da realidade e a atuação a partir de valores comuns". Paradigma, portanto, consiste em um modelo que é seguido, por considerar-se correto e verdadeiro para uma determinada época, em um determinado contexto. Quando os modelos praticados não satisfazem mais, começa a ocorrer o que se convencionou denominar "crise do paradigma". Esse momento não acontece de forma fácil e tranqüila, pois, como na maioria das mudanças, surgem resistências. É mais fácil e menos trabalhoso continuar mantendo a rotina.

O ensino tradicional, tal como o conhecemos, baseia-se no paradigma conservador. Nesse paradigma, os fatos, os conceitos, os conteúdos são considerados inquestionáveis, absolutos e que devem ser aceitos sem restrições. 0 conhecimento é transmitido de forma vertical, do professor - elemento principal no processo - para o aluno, neste caso, mero receptor do conteúdo transmitido. Nessa forma de relação entre professor e aluno, não se permite questionar, acrescentar ou discordar. O aluno recebe as informações e deve reproduzi-las da maneira como lhes foram repassadas. Deve manter-se passivo e submisso à autoridade daquele que ensina. É o professor quem decide o que vai ser "aprendido" pelos alunos e como será feita a transmissão do conteúdo. De um modo geral, a metodologia inclui aulas expositivas, exercícios de repetição e tarefas padronizadas, tudo no sentido de reforçar o "aprendizado" que aconteceria pela memorização do que é exposto pelo professor.

Com a crise do paradigma conservador na educação, houve a conseqüente mudança do modelo. O paradigma tradicional cedeu lugar ao paradigma inovador, que alguns autores denominam paradigma emergente. Neste novo paradigma, a reprodução do conhecimento cedeu lugar à produção do conhecimento. Educar adquiriu o sentido de incentivar a busca do conhecimento.

O Relatório para a UNESCO da Comissão Internacional sobre Educação para o Século XXI, elaborado por Delors (1999), esclarece de maneira significativa o novo enfoque educacional. Nele, relacionam-se os "quatro pilares" sobre os quais se assenta a educação: aprender a conhecer, aprender a fazer, aprender a viver juntos, aprender a ser. 
O aprender a conhecer implica a busca da informação, que, em seguida, deve transformar-se em conhecimento, pelo trabalho conjunto de professores e alunos. Não se deve mais aceitar uma única fonte de informação. É necessário buscar novas fontes, ou seja, é preciso "aprender a aprender".

Ligado a esse primeiro fundamento, encontra-se 0 aprender a fazer. É preciso formar profissionais que saibam utilizar na prática o que construíram na teoria. $O$ novo profissional deve estar consciente de que atualmente se exige o desenvolvimento das aptidões, competências e habilidades necessárias para desempenhar com êxito suas tarefas, sem negligenciar o trabalho em equipe.

Essa idéia alia-se ao terceiro pilar, ou seja, o aprender a viver juntos. É necessário saber respeitar a si mesmo e aos outros, a terra, a água, os seres vivos, em uma relação de interdependência. Ninguém vive só. A visão do todo torna-se parte fundamental e as diferenças devem ser respeitadas.

O quarto e último fundamento é o aprender a ser, que reforça e, de certo modo, resume os anteriores. A idéia nele contida contraria o que era defendido no paradigma newtoniano-cartesiano, no qual predominava a razão. Enfocando a educação com um sentido de totalidade, este fundamento considera que o indivíduo é mais do que simplesmente razão: é razão e emoção, corpo e alma, matéria e espírito. Behrens (2000, p.83), citando Gadotti, escreve que aprender a ser contempla "o desenvolvimento integral da pessoa: inteligência, sensibilidade, sentido ético e estático, responsabilidade pessoal, espiritualidade, pensamento autônomo e crítico, imaginação, criatividade, iniciativa".

O novo paradigma, ao incorporar essas visões, alterou profundamente o papel do professor e do aluno no processo ensino-aprendizagem. Nele, 0 professor deixa de ser o detentor do saber, a autoridade em conhecimento, e passa a ser um facilitador da aprendizagem. O aluno, por sua vez, sai da posição de receptor do conhecimento repassado pelo professor, para transformar-se num pesquisador reflexivo e crítico. Assim, ele é incentivado a buscar a informação e a produzir o conhecimento. Nessa busca, terá de aprender a pesquisar, questionar, discordar, discutir, propor, criar, enfim, tornar-se um estudante transformador e crítico.

\section{De Disciplina a Programa de Aprendizagem}

As aulas da então disciplina História da Fisioterapia não eram diferentes das que normalmente acontecem no ensino convencional. Eram aulas extremamente tradicionais, na sua maioria expositivas. Nelas, o conteúdo a ser "aprendido" era repassado aos alunos. Estes deveriam copiar, memorizar e 
responder corretamente às questões na temida prova bimestral. Resumia-se, portanto, no tradicional "escute, leia, decore, repita". Pode-se imaginar a dificuldade que os alunos tinham em aprender, por tratar-se de um assunto teórico, no qual fatos históricos e datas constituíam a base do que deveria ser ensinado. Não parecia existir alternativa que pudesse substituir essa metodologia, mesmo porque foi a metodologia que vinha sendo adotada por professores do Curso há vinte anos, aproximadamente. Considerava-se que era a melhor e, porque não dizer, a única.

A implantação do Projeto Pedagógico da Pontifícia Universidade Católica do Paraná, associada aos conhecimentos adquiridos no Curso de Mestrado desta Instituição, fez acontecer as mudanças. Foi preciso pensar numa reestruturação, pois a História da Fisioterapia passaria a compor um programa de aprendizagem unindo-se a outras duas disciplinas: Saúde Pública e Sociologia. Era preciso definir o "elo de ligação" das antigas disciplinas para que se formasse o novo programa, que foi denominado Determinantes Históricos, Sociais e Culturais da Fisioterapia.

As reuniões, para se pensar nas mudanças, foram extremamente proveitosas, principalmente porque as três professoras das disciplinas que iriam formar o programa de aprendizagem, encontravam-se ligadas pelo fato de serem alunas do Curso de Mestrado em Educação. Foram três docentes, pensando em mudanças e inovações metodológicas. Pensou-se, então, em substituir as tradicionais aulas expositivas por estudos de textos; propuseram-se temas para pesquisas bibliográficas e para sites específicos; discutiu-se, em pequenos e grandes grupos, sobre os temas propostos, projetaram-se pesquisas de campo. A preocupação passou a ser a valorização dos alunos e a forma de integrar as antigas disciplinas, estanques, em um programa de aprendizagem com atividades dinâmicas.

Sob uma nova visão, o Programa de Aprendizagem Determinantes Históricos, Sociais e Culturais da Fisioterapia foi, então, estruturado em cinco unidades de estudo, cada uma com um tema central. Os temas centrais propostos para estudo foram: Aspectos Históricos, Processo Saúde-Doença, Sociedade x Sistema de Saúde, Cidadania e Profissionalização e O Fisioterapeuta Enquanto Agente de Transformação Social. Cada professora, na sua área de conhecimento, passou a enfocar o tema relacionando-o com os assuntos tratados pelas outras duas docentes responsáveis pelo Programa. Cabe aqui explicitar que a professora responsável pelo estudo de Saúde Pública foi substituída, ao final do ano de 2000, por não ter mais carga horária para este programa específico. A professora que assumiu, Mestre em Saúde Pública pela Universidade Estadual de Ponta Grossa, continuou as atividades propostas anteriormente. Desse modo, não houve alterações nos temas de estudo em conseqüência da mudança de docente. 
Enfocando especificamente as mudanças que ocorreram com a assimilação da História da Fisioterapia, pelo programa de aprendizagem, pode-se observar um crescimento dos alunos em relação ao interesse pelos fatos históricos. Anteriormente, os fatos que influenciaram a Fisioterapia nos diferentes momentos da história eram repassados de maneira expositiva. Com o início do programa, a metodologia foi alterada para estudo de texto. Os alunos passaram a retirar de textos, fornecidos pela professora, os fatos mais importantes relacionados com a Fisioterapia nos diferentes períodos da História: Antigüidade, Idade Média, Renascimento, Período da Industrialização. Inicialmente, cada estudante passou a fazer um estudo individual. Depois, reunidos em equipes de três ou quatro alunos, cada equipe produzia um texto. Posteriormente, os diversos textos que resultavam do trabalho dos grupos eram utilizados para a construção de um texto único, como referencial para a turma toda.

Ao desenvolver esse tipo de atividade, os próprios discentes vão buscar conhecimentos sobre a profissão. Descobrem com surpresa, por exemplo, que na Antigüidade eram utilizados peixes-elétricos para o tratamento de doenças. Inclusive, ficam sabendo que, na época, as doenças eram chamadas de "diferenças incômodas". Entendem porque a Idade Média foi uma época de paralisação dos estudos relativos à saúde, quando a Igreja destacava que a doença era "algo divino". Observam que, com a volta do culto ao corpo, no Renascimento, passou a existir a preocupação em curar as doenças e prevenilas. É nesse período que a Fisioterapia começa a delinear-se como profissão. No Período da Industrialização, o destaque maior fica por conta das más condições de higiene e, também, das péssimas condições que apresentavam os locais e os regimes de trabalho, o que proporcionava o surgimento de epidemias. Com esses problemas, aliados a outros decorrentes das guerras que se sucediam, houve a necessidade de profissionais especializados para o tratamento das diferentes patologias que iam aparecendo. Nessa época, já era praticada e ensinada a Fisioterapia, embora de forma precária, para que fossem tratados os doentes e reabilitados os mutilados de guerra. A preocupação principal, porém, era manter o nível da produção industrial e pouco se pensava na saúde como melhoria da qualidade de vida.

O surgimento e o desenvolvimento da Fisioterapia no Brasil passaram, também, a ser estudados sob a forma de pesquisa. São repassados aos alunos itens importantes relacionados ao tema, que devem ser estudados para posterior discussão em sala de aula. Com isso, os estudantes são levados a conhecer como a profissão fisioterapia passou do nível técnico para o nível superior. Os graduandos, futuros profissionais, pesquisam sobre as leis que regem e sobre os órgãos que regulamentam a Fisioterapia, como o Conselho Federal e os Conselhos Regionais. Além disso, tomam conhecimento do Códi- 
go de Ética Profissional, que estabelece normas para o exercício da profissão. Ao se trabalhar o tema Processo Saúde-Doença, o enfoque se volta para os conceitos de cura, de reabilitação e de prevenção, e como esses conceitos se encontram contextualizados na Fisioterapia.

De posse de todos esses conhecimentos, os estudantes são levados a realizar uma pesquisa de campo, em diferentes áreas e locais de atuação do profissional fisioterapeuta. $\mathrm{O}$ objetivo é conhecer onde poderão atuar e quais os recursos fisioterapêuticos que poderão ser utilizados nessas áreas e nesses locais. O roteiro para a pesquisa é construído em sala de aula, com a contribuição das diferentes equipes de trabalho, levando-se em conta o que os alunos consideram importante saber, como, por exemplo, investimento profissional em cursos de pós-graduação, condições do mercado de trabalho, renda mensal, situação dos convênios de saúde, itens constantes dos roteiros de pesquisa dos anos de 2000 e 2001. Com essas visitas, os estudantes são levados a refletir como querem e, principalmente, como não querem ser em sua vida profissional. Entendem, também, que o paciente, como pessoa, deve ser o foco principal do atendimento e não os recursos econômicos de que ele dispõe para pagar a mais pelo tratamento a que está sendo submetido. Percebem que a concorrência do mercado de trabalho é grande, mas que para os bons profissionais sempre há lugar. Tomam conhecimento de que o profissional que não se atualiza está fadado ao insucesso. Finalmente, conscientizamse de que os profissionais devem lutar por uma remuneração justa, considerando que estão prestando um serviço de qualidade.

Ao final do semestre, é solicitada, pelas três professoras do programa de aprendizagem, uma pesquisa diagnóstica no intuito de pesquisar a inserção social do profissional fisioterapeuta. O roteiro é elaborado pelas docentes e inclui questões sociológicas, de saúde pública e de fisioterapia. No que diz respeito especificamente à fisioterapia, são apresentadas as seguintes questões para verificar o conhecimento do entrevistado sobre esta área de atuação:

- O que é Fisioterapia?

- Você sabe em quais casos a Fisioterapia atua? Em caso afirmativo, quais são?

- Você já utilizou tratamento fisioterapêutico?

- Caso tenha utilizado, o que tratou?

- Onde fez tratamento? (Clínica, hospital, associação, clube...)

- Qual o resultado obtido com o tratamento?

- Caso não tenha utilizado tratamento fisioterapêutico, conhece alguém que utilizou? Quem?

- Você considera o trabalho do fisioterapeuta importante? Por quê? 
As entrevistas são realizadas, no mínimo, com seis pessoas que pertençam a classes sociais diferentes. A intenção é observar se as pessoas conhecem a fisioterapia e o profissional fisioterapeuta. Nas pesquisas realizadas, durante os anos de 2000 e 2001, foram entrevistadas aproximadamente 350 pessoas. Para este artigo, foram analisadas 104 entrevistas, o que representa $29,71 \%$ do total.

Constatou-se que $24,03 \%$, ou seja, quase um quarto dos entrevistados não sabiam o que era a fisioterapia. Daqueles que conheciam esta área, $49,03 \%$ já tinham sido submetidos a este tipo de tratamento, 46,15\% tinham alguém na família ou das suas relações pessoais que havia utilizado tratamento fisioterapêutico, finalmente, $4,82 \%$ não conheciam a fisioterapia.

Outro fato interessante, constatado pela pesquisa, é que a grande maioria dos entrevistados, que conhecem a fisioterapia, cita como área de tratamento a ortopedia e a traumatologia $(64,64 \%)$, seguida pela neurologia (19,33\%), respiratória $(3,88 \%)$ e, por fim, as outras áreas (12,15\%), englobando aqui as áreas reumatológica, preventiva, obstétrica, odontológica e estética. Os locais de tratamento mais citados são: clínica $(74,15 \%)$, hospital $(14,62 \%)$, domicílio $(6,74 \%)$ e outros $(4,49 \%)$. Em relação ao resultado obtido com o tratamento, 63,53\% relataram melhora total, 30,59\% relataram melhora parcial, e 5,88\% não obtiveram mudança em relação ao quadro inicial.

Ao concluir suas pesquisas, apesar dos resultados obtidos com a análise dos dados, os estudantes apontam a necessidade de melhorar o marketing em relação à fisioterapia como profissão, pois, ela faz parte da área da saúde e, como tal, deve ser conhecida, para que possa beneficiar mais pessoas. Isto fica claro quando são analisadas as respostas relacionadas à importância do trabalho do fisioterapeuta. Do total de entrevistados, $100 \%$ responderam que o trabalho desse profissional é importante, porém, apenas 72,11\% souberam explicar o porquê dessa importância.

\section{Considerações Finais}

A passagem de História da Fisioterapia, como disciplina, para Determinantes Históricos, Sociais e Culturais da Fisioterapia, como programa de aprendizagem, foi causa de profundas transformações no Curso de Fisioterapia da PUCPR. Alteraram-se as formas de apresentação das atividades docentes e discentes e mudou o enfoque pedagógico. Com isso, transformou-se o aluno, que passou a ser um estudante mais crítico e reflexivo, preocupado com o seu futuro e com o futuro da sua profissão. Surgiu, então, a necessidade de se pensar como poderão ser solucionados os problemas "diagnosticados" nos trabalhos ao longo do semestre. Portanto, esses alunos tornaram-se pesso- 
as empenhadas em aprimorar seus conhecimentos, para poder prestar o melhor atendimento ao paciente e mostrar que atuam na sua profissão de modo ético e, também, preocupados com o lado humano.

Pelo que foi exposto, pode-se ressaltar que a mudança gerada pela implantação do Projeto Pedagógico na PUCPR foi extremamente positiva em relação à História da Fisioterapia. O que era abordado em aulas teóricas passou a exigir que os estudantes fossem a campo verificar o que acontece na profissão. Eles, alunos, foram buscar conhecimento por meio de pesquisas. Portanto, os estudantes deixaram de somente receber e passaram também, a construir conhecimento.

Pode-se afirmar que a semente para a formação de cidadãos críticos, reflexivos, éticos e humanos está sendo plantada a cada primeiro período do Curso de Fisioterapia. Cabe aos professores e alunos dos períodos subseqüentes regarem essa semente, para que ela possa crescer e produzir bons frutos.

\section{Referências}

ARANHA, M. L. A. História da educação. São Paulo: Modema, 1996.

BEHRENS, M. A. A aprendizagem colaborativa num paradigma emergente. In: BEHRENS, M.; MASETTO, M.; MORAN, J. M. Novas tecnologias e mediação pedagógica. Campinas: Papirus, 2000.

DELORS, J. et al. Educação: um tesouro a descobrir. Relatório para a UNESCO da Comissão Internacional sobre Educação para o século XXI. São Paulo: Cortez; Brasília: UNESCO/MEC, 1999.

DIRETRIZES PARA O ENSINO DE GRADUAÇÃO: o projeto pedagógico da Pontifícia Universidade Católica do Paraná. Curitiba: Champagnat, 2000. 